\title{
AS HORTAS URBANAS E A FUNCÃO SOCIAL DA PROPRIEDADE INSTITUÍDA NA CONSSITUIÇÃO
}

\author{
Ana Thais Freitas Borges* \\ Cecilia Maria Cardoso Freitas ${ }^{*}$ \\ Kleycilene de Jesus Nunes Santos ${ }^{* * *}$ \\ Maria Cecilia de Freitas Borges ${ }^{\star \star * x}$
}

RESUMO: Este estudo é fundamentado nos ditames do "Estatuto das Cidades", lei federal $\mathrm{n}^{0}$. 10.257, leis do estado do Maranhão e na Constituição da República Federativa do Brasil que institui, dentre os direitos individuais e coletivos, que a propriedade atenderá a sua função social. Daremos enfoque no aprimoramento social à evolução dos direitos concernentes aos espaços urbanos que geram grandes expectativas de progressos aplicados a políticas habitacionais advindas, sobretudo, dos reclamos dos movimentos populares organizados, que apontam uma mudança nos rumos do processo e apropriação do espaço urbano nas cidades brasileiras. No entanto, a implantação dessas leis têm encontrado sérias barreiras que dificultam a caminhada no sentido de construção de cidades ambientalmente equilibradas e socialmente mais justas. Para chegar a esta solução de cunho social urbano, o trabalho contou com fundamentação legislativa urbanística do município de São Luis, projeto arquitetônico, teoria básica sobre agroecologia, paisagem, tecnologias sustentáveis.

PALAVRAS-CHAVE: Agricultura urbana; Estatuto; Função social.

\section{URBAN KITCHEN GARDENS AND THE SOCIAL FUNCTION OF LAND PROPERTY IN THE BRAZILIAN CONSTITUTION}

ABSTRACT: Current analysis is foregrounded on City Statutes, Brazilian federal law 10.257, legislation of the state of Maranhão, Brazil, and on the Brazilian Constitution, which establishes, within individual and collective rights, the social function of land. The evolution of rights to urban spaces is underscored within social improvement. They provide expectations for progress applied to habitation policies derived from claims of popular movements that indicate changes in trends and in the appropriation of urban space in Brazilian cities. The establishment of these laws has impaired the construction of environmentally balanced and socially more just cities. Current analysis delved into urban legislation in the municipality of São Luis, Brazil, architectonic projects, basic theory on agro-ecology, landscape and sustainable technologies.

KEYWORDS: Urban agriculture; statute; social function.

\section{INTRODUCAO}

A política urbana foi esculpida na Constituição Federal de 1988 nos artigos 182 e 183 onde a concepção sociológica de desenvolvimento urbano tem por objetivo ordenar as plenas funções de integração humana da cidade, protegendo os ecossistemas existentes para evitar a degradação e garantir o bem- estar de seus habitantes. A constituição aponta nas competências dos entes federativos que deverá ser executada pelo poder municipal (área de abrangência intraurbana), pois cada cidade por meio de seus planos diretores e leis orgânicas municipais sabem exatamente onde e como aplicarem seus investimentos

\footnotetext{
Graduada em Arquitetura e Urbanismo; Universidade Estadual do Maranhão (UEMA), Brasil; E-mail: borges.ana.atf@gmail.com

** Especialista em Direito Civil e Processo Civil; Instituto Federal do Maranhão (IFMA) Brasil.

*** Discente do Curso Técnico em Meio Ambiente do Instituto Federal do Maranhão (IFMA) Campus Maracanã, Brasil.

**** Graduanda em Design; Universidade Estadual do Maranhão (UEMA), Brasil
} 
além de receberem incentivos diretos da política nacional de desenvolvimento urbano em conjunto com as políticas em geral instituídos nos princípios da ordem econômica e os instrumentos das políticas de desenvolvimento e de expansão urbana.

0 estatuto da cidade diz que os traçados urbanísticos dos planos diretores estão condicionados aos princípios ambientais constitucionais e do direito urbanístico a fim de cumprir a sua função social específica propiciador de habitações dignas, preservações do meio ambiente, aproveitamento racional dos espaços ociosos, condições apropriadas de trabalho recreação e circulação humana impondo aos descumpridores imposições, sanções administrativas como 0 parcelamento do solo, edificações compulsórias, impostos progressivos no tempo e, por fim a desapropriação. A partir do $1^{\circ}$ Fórum Social Mundial inicia-se a construção de uma Carta Mundial do Direito à Cidade, iniciativa do Fórum Nacional de Reforma Urbana e de inúmeras redes internacionais que foram se somando ao longo do processo. A difusão do Estatuto serviu como modelo de discussão e, especialmente na América Latina que sofre desde as colonizações grandes expurgos de contingentes populacionais das cidades. Essa difusão se deu em inúmeros sistemas de governo e também da sociedade, por meio das redes de organizações sociais, e analisamos que ainda resta muito a fazer pela plena implementação do Estatuto em nossas cidades. Observamos importantes pontos de vista nas palavras do professor José Afonso da Silva, in curso de Direito Constitucional Positivo:

São necessárias sua apropriação e reivindicação por mais organizações. É preciso fazer valer o que foi conquistado nos planos diretores, nas áreas ocupadas, nos enfrentamentos aos grandes interesses da especulação imobiliária e das grandes corporações. [...] 0 principal, no entanto, é a consciência é que a lei não é uma ferramenta que age por si só" 0 grande impasse é que no Brasil não se tem a divulgação de direitos e deveres a toda população como uma praxe normal [...] e sim os direitos permanecem numa casta fechada onde somente poucos têm acesso e conhecimento para usufruírem de seus benefícios (SILVA, 2015, p. 715).

0 direito à moradia digna e acesso à conseguinte titulação dessas é, com certeza, um instrumento a mais na mão da sociedade brasileira, mas somente com a mobilização e organização podemos aliar a ferramenta institucional com a pressão política e a organizações de associações populares para exigir as mudanças necessárias. As condições para mudanças estruturais nas cidades não podem estar alienadas ao modelo de sociedade onde vivemos atualmente, pois devemos construir cidades justas e solidárias e isso faz parte de um processo de transformação integral. Trazemos apontamentos demonstrando a importância do cumprimento da função social da propriedade por meio da apresentação de solução ambientalmente corretas com estruturado, complexo e detalhado estudo arquitetônico com apresentação de projeto de uma complexa área de hortas, produção e vendas, localizados na avenida Presidente Médici, bairro de Fátima em São Luís - Maranhão, onde deverá funcionar mercados, centro administrativo comunitário com estufas e depósito de material de produção, granja, meliponário, jardim sensorial além de áreas verdes com equipamentos de lazer. Este trabalho traz às hortas urbanas como forma de cumprimento de lei ao uso adequado do solo cumprindo sua destinação urbanística e em obediência ao princípio da ordem econômica assegurando a todos uma existência digna como preceitua a carta magna. Apresenta um estudo que adequa a correta funcionalidade social desse espaço ocioso da cidade de São Luís e em todas as suas fases busca evitar 0 sub-aproveitamento desses na cidade, além de servir o presente estudo como exemplo a ser aplicado nas demais regiões do Brasil.

Em cumprimento ao princípio da livre iniciativa, propomos nesse estudo a instalação de um centro de produção de alimentos "modelo funcional de horta urbana" em São Luís, bairro de Fátima, com estruturas de lazer, estudos e pesquisa fundamentando o direito 
à alimentação saudável, ao respeito do ciclo natural das águas, produção correta, manuseio de compostos orgânicos, reciclagem, tratamento dos compostos orgânicos. Produção de insumos próprios respeitando a cultura e os hábitos alimentares locais com preços acessíveis; segurança alimentar aplicada à dignidade da pessoa humana proporcionando lazer e integração social. Os princípios da ordem econômica conectamse à educação ambiental, às ciências naturais e, por conseguinte, à reinserção social com criações de áreas contemplativas que privilegiam 0 esporte e 0 lazer. $\mathrm{Na}$ autonomia coletiva, o poder das pessoas se sobressai dentre vários tipos de organizações públicas, pois a comunidade torna-se parte principal com potencial de criação e com esses potenciais de desenvolvimentos ativados torna-se fator atrativo a financiadores públicos e particulares e demais empresas que proponham parcerias financeiras. Conceder apoderamento às comunidades para construírem suas próprias resistências, opinar e modificar suas áreas de moradia e conseguirem suprir planejamento de curto, médio e longo prazo para minimizar os efeitos ruins das crises urbanísticas, além de torná-las mecanismos de proteção contra as vulnerabilidades sociais. 0 presente trabalho apresenta propostas esquematizadas e soluções de estudos estatísticos que demonstram a sua plena viabilidade evitando o fracasso.

\section{METODOLOGIA}

Para iniciar esse trabalho e a sua fundamentação teórica, trazemos o conceito instituído no parágrafo único do artigo $1^{\circ}$ do estatuto das cidades, em que este preceitua de forma conceitual o objetivo do documento: obediência às regras de direito público, estabelecendo 0 ordenamento das cidades, ditames normativos da titulação de propriedades, interesse social que regulam 0 uso da propriedade urbana em prol do bem coletivo, da segurança, bem-estar dos cidadãos, bem como do equilíbrio ambiental. Nossos estudos buscarão compor um panorama de ordem baseado na prática real de um projeto que demonstra como as leis, a arquitetura e 0 urbanismo trazem soluções ambientalmente corretas às cidades aderindo à nova maneira de se considerar 0 espaço urbano. Há modificações na antiga visão fundamental instituída, em que novos apontamentos constitucionais demonstram pelo cumprimento dos princípios ecológico, democrático e da participação popular o direito ao meio ambiente equilibrado e desenvolvido no curso de detalhamento desses estudos aos níveis de potencial produção e recuperação de áreas urbanas degradadas dando-Ihes uma finalidade econômico-social com a implantação de hortas, centro de estudos e áreas de lazer nos terrenos ociosos na cidade de São Luís - Maranhão.

A legislação urbanística básica de São Luís, composta pela lei de uso e ocupação de São Luís e 0 código municipal de obras, foi consultada para informações sobre ocupação e uso do solo. 0 entorno do local escolhido foi estudado, a fim de verificarem as principais carências da área, por meio de pesquisa de campo, aplicação de questionário em que com base em respostas obtidas foram gerados gráficos que ajudaram a buscar um produto que se integrou ao perfil dos moradores e suas necessidades básicas.

\section{RESULTADO}

Como resultado do processo a elaboração de um estudo preliminar de empreendimento adequado ao uso de produção alimentícia para comercialização e estudos a serem aplicados na avenida Presidente Médici, bairro Areinha, em São Luís - Maranhão, gerando ainda um programa de necessidades que poderá ser utilizado em situações correspondentes ao caso estudado.

\section{DISCUSSAO}

0 presente trabalho apresenta um projeto conceito de uma horta urbana na avenida Presidente Médici, em São Luís. 0 trabalho demonstra que este equipamento de lazer (qual?) poderá contribuir como efeito mitigador local à crise de alimentos que hoje ocorre em muitas regiões do planeta. A crise de ali- 
mentos ocorre por condições climáticas como 0 aquecimento global ou mesmo por condições precárias de logística e transporte pelas quais se tem o exemplo de muitas cidades brasileiras para obter produtos de boa qualidade e valor nutricional tão necessário à alimentação básica.

Observa-se que muitos desses problemas têm relação com oscilações de demanda e oferta no mercado de grandes produtores alimentícios bem como das grandes redes de supermercados, gerando-se uma condição de obtenção de alimento muitas vezes inacessível para a população de classe baixa. Em países em desenvolvimento, a exemplo do Brasil, observa-se constantemente 0 custo de produtos básicos, como o tomate ou a carne bovina, aumentar de forma significativa a ponto de sobrecarregar o orçamento de uma família padrão moradora de uma grande cidade.

A crise atinge tais proporções que inviabiliza 0 desenvolvimento do pequeno produtor nas zonas rurais. Muitos desses, sem 0 apoio técnico e de incentivo de governos, transferem-se para o "ambiente de trocas" seletivo e priorizador da cidade que dá privilégio a quem obteve melhor educação.

São observados também fatores de risco nos quais os alimentos são produzidos devido ao crescente uso de insumos artificiais para obter-se um alimento de boa aparência e gosto, sem pensar no respeito aos ciclos e recursos naturais. Assim, 0 alimento chega à mesa das pessoas com alta carga de produtos tóxicos, oneração por impostos, resultante do esforço da manutenção da produção, transporte e logísticas lentos, caros que compõem o grid de mercados e supermercados e grandes propriedades produtoras.

0 consumo de alimentos com agrotóxicos aumentou bastante no Brasil e é exemplificado pelo Dossiê da Associação Brasileira de Saúde Coletiva (ABRASCO):

0 cenário do mercado de agrotóxicos, atualizado para 2010, mostra que nesse ano houve um acréscimo de $190 \%$. As maiores empresas que controlam esse mercado são multinacionais instaladas no Brasil: Basf, Bayer, Dupont, Monsanto, Syngenta, Dow. Em 2010, eram $22 \%$ na América Latina, sendo $19 \%$ no Brasil, o maior mercado de agrotóxicos do mundo, seguido pelos EUA. Observam-se acordos e fusões de empresas que dominam ao mesmo tempo o mercado de agrotóxicos e de sementes. A estrutura de mercado mostra os acordos comerciais entre as empresas, tais como os da Bayer com a Monsanto e da Basf com a Monsanto (núcleo controlador de acordo de todos). No entanto, muitos deles envolvem acordos públicos com a Empresa Brasileira de Pesquisa Agropecuária (EMBRAPA). 0 montante mobilizador é maior que o PIB de vários países, o que os constitui como verdadeiros oligopólios. Há um mercado dos registros de agrotóxicos mediados por empresas de fachada (CARNEIRO, 2015, p. 108).

De acordo com Aquino e Assis (2007), é observado em contrapartida que a produção orgânica vem se tornando uma prioridade em nível mundial, quando se observa um padrão de avanços de estudos de desenvolvimento de tecnologias para melhoramento da produção na área de agrobiologia e produção alimentícia 100\% orgânica. Enquanto os países desenvolvidos como a Dinamarca e a Holanda investem em tais pesquisas com uso de tecnologias para produção de alimentos em condições adversas de clima e espaço, nos países em desenvolvimento busca-se garantir o mínimo estipulado pela Organização das Nações Unidas para Agricultura e Comida (FA0) em relação a condições ecológicas, de saúde pública e valorização de aspectos socioeconômicos locais para promover 0 desenvolvimento sustentável.

\subsection{O ESPAÇO URBANO EM CRISE}

De acordo com Aquino e Assis (2007, p. 137):

A urbanização não planejada se apresenta como um dos principais problemas da humanidade. A Organização das Nações Unidas para Agricultura e Comida (FAO) (1998) estima que, para 0 ano de 2015 , mais de 26 cidades em todo o mundo estarão com mais de 10 milhões de habitantes. Para alimentar essa população, de acor- 
do com a Organização as Nações Unidas para Agricultura e Comida (FA0) (1998), seria necessário importar pelo menos 6.000 toneladas de alimentos por dia. Dessa crescente urbanização, além do fornecimento de alimentos, resultam outros problemas como a preservação ambiental e a oferta de empregos.

Com isto, é possível observar-se que as cidades têm crescido de forma muito rápida desde os processos de industrialização em meados do século XVIII e XIX. 0 mesmo contingente de pessoas, que produzia em zonas rurais, passou a migrar para cidades, de modo a alterar completamente suas dinâmicas sociais e econômicas, passando a consumir muito mais rapidamente os insumos do que o tempo que levou para produzi-los.

$\mathrm{Na}$ cidade de São Luís tem sido possível observar essa tendência de maneira comum a grandes cidades por se tratar de região metropolitana que foi agregando, em seu crescimento urbano, grande concentração de serviços e produtos. De acordo com os estudos de Burnett (2012), a taxa de urbanização da cidade alcançou uma faixa de $94,5 \%$ somente no ano de 2010. A produção agropecuária da região Norte maranhense, onde se inclui São Luís, representa 17,8\% da produção de todo o Estado, estando em segundo lugar em relação à região 0este do Maranhão. Ainda de acordo com Burnett (2012), a cidade atrai uma gama de investimentos por parte da indústria alimentícia. Por exemplo: Ambev, 144 milhões; Atacadão, 35 milhões; Mateus Supermercados, 90 milhões; Maciel, 4 milhões. Negócios que refletem a alta demanda de sua população urbana que ocupa os diversos locais da cidade pela comodidade de se viver em um ambiente urbano.

É importante observar que, tendo em vista essa conjuntura, estão diretamente relacionados problemas da ordem ambiental que trazem desequilíbrio e sobrecarregam o ecossistema antes existente. Fenômenos como a impermeabilização do solo ou mesmo o surgimento de ilhas de calor influenciam completamente os ciclos de água e do ar, atraindo uma raiz de proble- mas que está diretamente e indiretamente relacionada, de forma a entender-se que a perda significativa de áreas verdes também influencia a perda de espaços de recreação, bem-estar e saúde além de causas de doenças relacionadas a estes fatores.

\subsection{LUGAR DA AGRICULTURA NA CIDADE}

A agroecologia e a produção orgânica são conceitos relacionados que buscam ecossistemas sustentáveis e de completa integração com os meios biológicos e contextos de convívio social, sendo a agricultura o meio onde é possível observar uma determinada evolução.

Logo, pressupõe-se a mesclagem do respeito à natureza mediante 0 desenvolvimento de tecnologias que tenham objetivo melhorador dos processos naturais, incrementando os produtos obtidos de forma a gerar satisfação do ser humano que investe em agroecologia.

Em São Luís, uma cidade de população em torno de 1.309.330 habitantes, a relação homemcultivo e animal pode ser citada por meio do entendimento do seu próprio processo histórico, de cidade base militar a entreposto comercial, passando por polo industrial até chegar finalmente ao título de grande região metropolitana no Maranhão, onde atualmente as atividades de comércio e serviços predominam entre as atividades de maior movimentação econômica na região. (BURNETT, 2012).

A atividade hortifrutigranjeira de caráter orgânico, na região metropolitana de São Luís, é desenvolvida em menor expressividade do que a anteriormente citada (pesca). Dentre os motivos estão a se considerar o pouco apoio governamental para 0 desenvolvimento econômico dos polos produtores da cidade, os elevados custos em investimentos na produção de hortaliças para competição no mercado existente, e a falta de mão de obra interessada em trabalhar nestas zonas periurbanas. Esses aspectos puderam ser considerados graças a um exemplo de produção orgânica em São Luís, obtido por meio de pesquisa de campo que será citado no capítulo 3 deste trabalho. 
Assim, a produção agrícola nas cidades podese justificar por inúmeras razões tais como escassez de oportunidades na cidade, o surgimento de um nicho de consumidores, a exigir produtos cada vez mais saudáveis, aumento de disponibilidade tanto de espaços, visto que não necessita de extensas áreas para se desenvolver, pois funciona como excelente maneira de reduzir a marginalização dando às pessoas a capacidade de tomar decisões por si próprias e por suas comunidades promovendo maior segurança alimentar.

\subsection{APLICAÇÃO DE ESTUDO NA ÁREA ESCOLHIDA: AVENIDA PRESIDENTE MÉDICI}

Nessa área foram aplicadas pesquisas de campo para levantamento de informações de base para dados principais dos entrevistados, informações sobre as pessoas da família a exemplo do nível de escolaridade, da renda, do local de trabalho, das despesas obtidas por meio de um questionário de entendimento de tais questões.

Esses dados revelam-se importantes por relações de informações básicas dos possíveis usuários e da área a ser considerada de forma a gerar-se um projeto que se integre 0 máximo possível à realidade local.

A descoberta do terreno deu-se com base em interesse por mapa localizado em pesquisa feita no Livro Leitura Urbana São Luís - Diagnóstico revisão da Lei de Zoneamento, Parcelamento, Uso e Ocupação do Solo, onde é possível observar manchas de vazios urbanos presentes na área da cidade. (BARBOSA; ESPÍRITO SANTO; TRINTA, 2014).

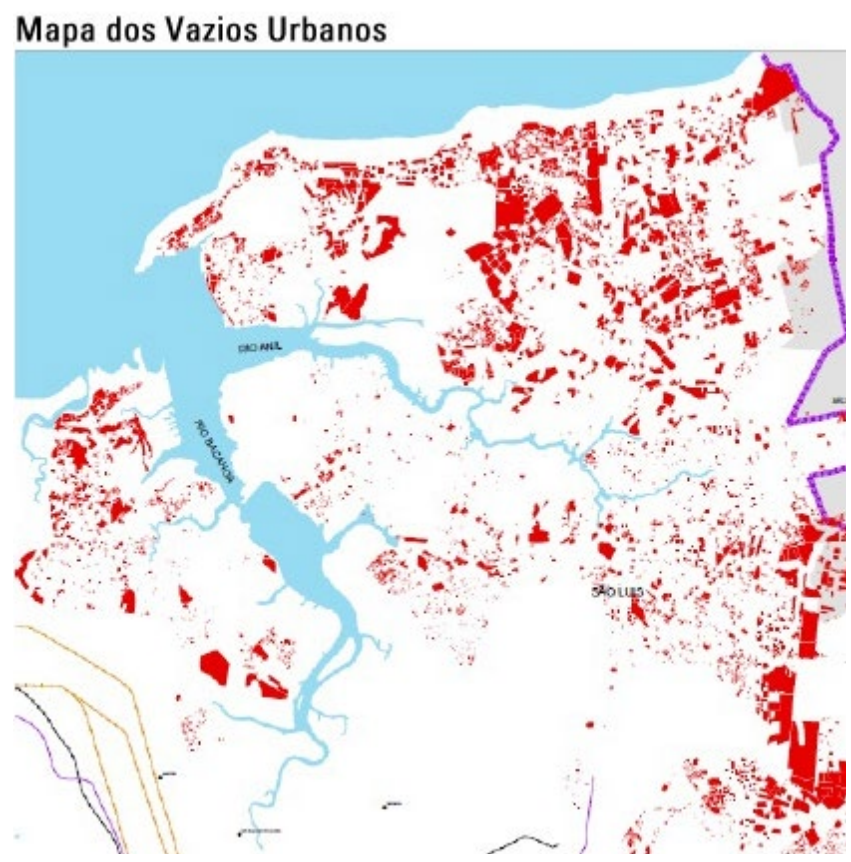

Figura 1. Representação vazios urbanos da cidade Fonte: INCID (apud BARBOSA; ESPÍRITO SANTOS; TRINTA, 2014).

A escolha do terreno ocorreu ainda devido a estudos de viabilidade para implementação de uma fazenda urbana neste terreno, por aspectos como a fácil localização, evidência do terreno para com a avenida principal que possui considerável fluxo em São Luís, terreno com topografia de pouca declividade propícia ao plantio de hortaliças além de ser uma forma de suprir as carências a serem observadas a seguir, proporcionando uso comunitário para uma área abandonada.

Os fluxos predominantes, que ocorrem no entorno da área de intervenção, são as duas avenidas primárias - senador Vitorino Freire e Presidente Médici e as ruas de influência sobre o terreno, ruas 21 , 26, 30 e avenida Jaime Tavares, sendo possível ainda identificar ao todo sete paradas de ônibus próximas ao terreno.

A área escolhida, como já referido localiza-se na avenida Presidente Médici, no início da avenida; no bairro da Areinha encontra-se circundado pela rua 21, rua 26 e rua 30 , porém esta última não tem ligação ao terreno pelo fato de estar murado no fundo. 


\subsection{RESULTADOS OBTIDOS NAS ENTREVISTAS AOS MORADORES DO ENTORNO}

Em relação ao bloco um da pesquisa referente aos dados básicos dos entrevistados, foram entrevistadas 12 pessoas residentes nas imediações do terreno durante os dias 16 e 17 de setembro de 2015, com diferentes perfis em relação a suas ocupações, muitas delas trabalhando de maneira informal, enquanto outros em empresas e ou ainda apenas estudando.

Em relação à idade, a maioria das pessoas entrevistadas encontra-se em fase adulta.

Em relação ao bloco 2 da pesquisa, foram coletados dados relacionados ao rendimento econômico da família. Dentre os entrevistados, oito mulheres e quatro homens, ainda, seis dos 12 entrevistados, por meio da coleta de dados de renda, tinham 0 homem como responsável pela maior renda de sustento em relação às outras pessoas da família, enquanto três famílias auferiam a maior renda por meio das mulheres para sustento da família; e dentre as outras três famílias restantes, em duas delas, homens e mulheres auferiam renda na mesma proporção e uma possuía apenas um homem que estava aposentado.

Dentre as despesas mais caras foi possivel observar como 0 gasto com alimentação é uma quantia considerável dentre os dispêndios mais altos. Em uma das famílias foi observado um gasto de $\mathrm{R} \$ 1.300,00$ apenas com alimentação, em uma média de $\mathrm{R} \$ 300,00$ a $\mathrm{R} \$ 800,00$, o transporte e a luz vêm em segundo e terceiro lugares, respectivamente, como os dispêndios mais altos.

No bloco 3 da pesquisa procurou-se colher dados a respeito das características das moradias, considerando-se que 0 entorno da área do terreno possui uso predominantemente residencial. Apenas um dos 12 entrevistados possuía casa alugada enquanto a maioria era dentetora da casa própria. Todos os entrevistados afirmaram obter água encanada através da rede geral (Caema).

Dentre as 12 pessoas entrevistadas sobre a relação com a agricultura urbana, dois destes entrevistados participaram de projetos vinculados à pre- feitura e à universidade e um deles plantava frutas $\mathrm{e}$ hortaliças em sua casa.

Em relação às maiores dificuldades na prática da agricultura urbana, a falta de incentivo governamental figura entre as principais razões, seguidas de carência da administração local e, por último, todas as alternativas anteriormente citadas.

Dentre as respostas obtidas acerca do que poderia ser melhorado para incentivar projetos de hortas urbanas na área, foi referido maior quantidade de investimentos do governo local, maior investimento em profissionais com conhecimento técnico apropriado para tal prática, bem como mais incentivos e benefícios básicos para estimular atividade relacionados a questões de saúde, educação e segurança por se tratar de um terreno sem uso pelas pessoas do local.

\subsection{ESTUDO DA LEGISLAÇÃO DO MUNICÍPIO DE SÃO LUÍS}

De acordo com a legislação urbanística Básica de São Luís, na lei municipal de uso e ocupação do solo, lei 3.253 de 29 de dezembro de 1992 que dispõe sobre 0 zoneamento, parcelamento, uso e ocupação do solo urbano e dá outras providências, o terreno encontra-se na ZR3 (Zona Residencial 3) onde todos os usos permitidos são - todos $\mathrm{R}$, todos $\mathrm{C} 1$, todos $\mathrm{C} 2$, C3.1, C3.2, C3.5, todos E1, E2, I1.

$A$ atividade que se objetiva implementar nesta área infelizmente não possui regulamentação por esta lei, sendo necessário mesclar todos os usos do projeto com os usos que estão regulamentados nessa lei.

Ainda considerando-se essa lei, o terreno possui testada de frente para a avenida Presidente Médici, que é um Corredor Primário $\mathrm{CP}$, sendo os usos permitidos - todos R, todos C, todos S, todos E e II. In Verbis:

Art. 128 - A ocupação dos lotes pelas edificações é disciplinada pelas seguintes normas:

I. Área Total Máxima de Edificação (ATME) igual a $320 \%$ (trezentos e vinte por cento) da área do terreno; II. Área Livre Mínima do Lote 
(ALML) igual a $40 \%$ (quarenta por cento) da área do terreno para edificações unifamiliares, e $30 \%$ (trinta por cento) para as demais edificações;

III. 0 afastamento frontal mínimo das edificações igual a $30,00 \mathrm{~m}$ (trinta metros), a partir do eixo da via, exceto para a Av. dos Holandeses, com afastamento mínimo de 20,00 m (vinte metros);

IV. Gabarito máximo permitido de 12 (doze) pavimentos. (SÃO LUÍS, 1992, p. 37).

De acordo com a lei $n^{0} 4.590$, de 11 de janeiro de 2006, que dispõe sobre a construção, reconstrução e conservação de muros e calçadas e dá outras providências. In Verbis: Art. $1^{\circ}$ Considerando que a propriedade urbana deve cumprir sua função social, entendida como tal àquela em que 0 uso e ocupação obedecem às exigências fundamentais da sociedade, consolidada nas diretrizes do Plano Diretor e a lei de zoneamento, parcelamento uso e ocupação do solo, em conformidade com os dispositivos de instrumentação legal, os muros, calçadas e vedação de imóveis de São Luís ficam sujeitos ao que dispõe esta lei. (SÃO LUÍS, 2006, p. $1)$.

0 terreno encontra-se em desuso e abandonado e seu estado gera preocupação com a segrança dos que moram em seu entorno. Mesmo possuindo um dono, deixa de cumprir sua função social. Ainda sobre esta lei tem-se como obrigatoriamente a todos os proprietários de terrenos no perímetro urbano de São Luís a construção da estrutura de muro e calçadas que circundam seus lotes sob pena de desapropriação se 0 mesmo representar ameaça e segurança à saúde pública. In Verbis:

Art. $17 \mathrm{~A}$ bem do interesse público, o Município poderá promover a desapropriação do terreno quando houver risco a população, quer por representar ameaça a saúde ou segurança.

Parágrafo Único - 0 valor da desapropriação será calculado com base na planta genérica de valores do município descontado os valo- res devidos a todos os impostos e taxas incidentes ao imóvel. (SÃO LUÍS, 2006, p. 6).

0 programa de necessidades expressa $00 b-$ jetivo de promover a humanização, a acessibilidade e a discussão sobre 0 que vai ser produzido, vendido e criado nesse polo, dando aos cidadãos da cidade completa autonomia para decidir sobre as possibilidades, sobre as metas, além de desenvolvimento da visão do empreendimento sob o princípio de construção e fortalecimento da sutentabilidade local usando das potencialidades disponíveis.

0 propósito do estudo preliminar foi integrar informações colhidas da área além da análise de diversos fatores existentes que possam influenciar 0 funcionamento da horta urbana.

0 estudo preliminar foi dividido em setores, para melhor entendimento do projeto. Foram estabelecidos seis setores de acordo com o programa de necessidades anteriormente visto. São eles - acessos, mercado, administração, lazer, pró-atividade e área técnica.

Na parte próxima à avenida encontra-se o estacionamento que possui 76 vagas para carro, possuindo observância de acordo com as normas de acessibilidade NBR 9050 (2015). Como acesso têm-se ainda as calçadas que contornam o terreno bem como os caminhos que estão nos passeios ajardinados; 0 acesso de serviço é feito na parte lateral do terreno onde há vagas para quatro caminhões grandes. Nessa mesma área uma via interna facilita a entrada e saída destes veículos.

A área técnica do polo localiza-se no centro administrativo e comunitário onde estão os reservatórios de água fria térreos com capacidade cada um de 22.000 L e um reservatório de água pluvial com capacidade de $7.000 \mathrm{~L}$ que está localizado na cobertura do prédio do centro administrativo. No futuro é esperado que a água do alagado, que atualmente encontra-se degradado, venha a ser recuperada da poluição e utilizada para irrigação das culturas de acordo com sua capacidade de cheia.

Também pertencente a esse setor técnico têm-se 28 pontos de coleta seletiva que estão distri- 
buídos por todo 0 terreno para fins de ação em conscientização do valor que os resíduos possuem para boas práticas, como a compostagem e a reciclagem.

0 setor do mercado tem a proposta de vender os produtos plantados no local e contêm 32 quiosques que estão dispostos em dois tipos diferentes de layout, um adequado à venda de hortaliças, frutas e ervas; $\mathrm{e}$ outro, para a venda de comida de rua. Cada quiosque possui ainda sua área de depósito integrada com seu layout específico. Nessa mesma área do mercado têm-se ainda os banheiros masculino e feminino e áreas externas com mesas e cadeiras da praça de alimentação.

0 setor administrativo é composto pelo centro administrativo que possui a função de processar e armazenar os produtos obtidos da horta, apiário e granja para a venda no mercado, bem como decidir e orga- nizar os insumos necessários às referidas produções. 0 prédio está localizado na área central, possui integração com 0 centro comunitário. Possui salas para 0 processamento e armazenamento dos produtos, duas recepções para informação a visitantes, vestiários para ambos os gêneros, banheiros e sala de reunião. As estufas ficam próximas ao prédio administrativo $\mathrm{e}$ têm função de garantir que as sementes produzidas disponham de adequadas condições de germinação para posterior transferência ao solo. Ainda pertencente ao setor administrativo tem-se a casa de depósito de materiais da horta que se localiza próximo da estufa.

0 setor de proatividade é representado pelos prédios do centro comunitário, casa de Sanitização e higienização, granja e melíponário. Também pertencentes a este setor nas áreas externas estão a horta e a área de compostagem.

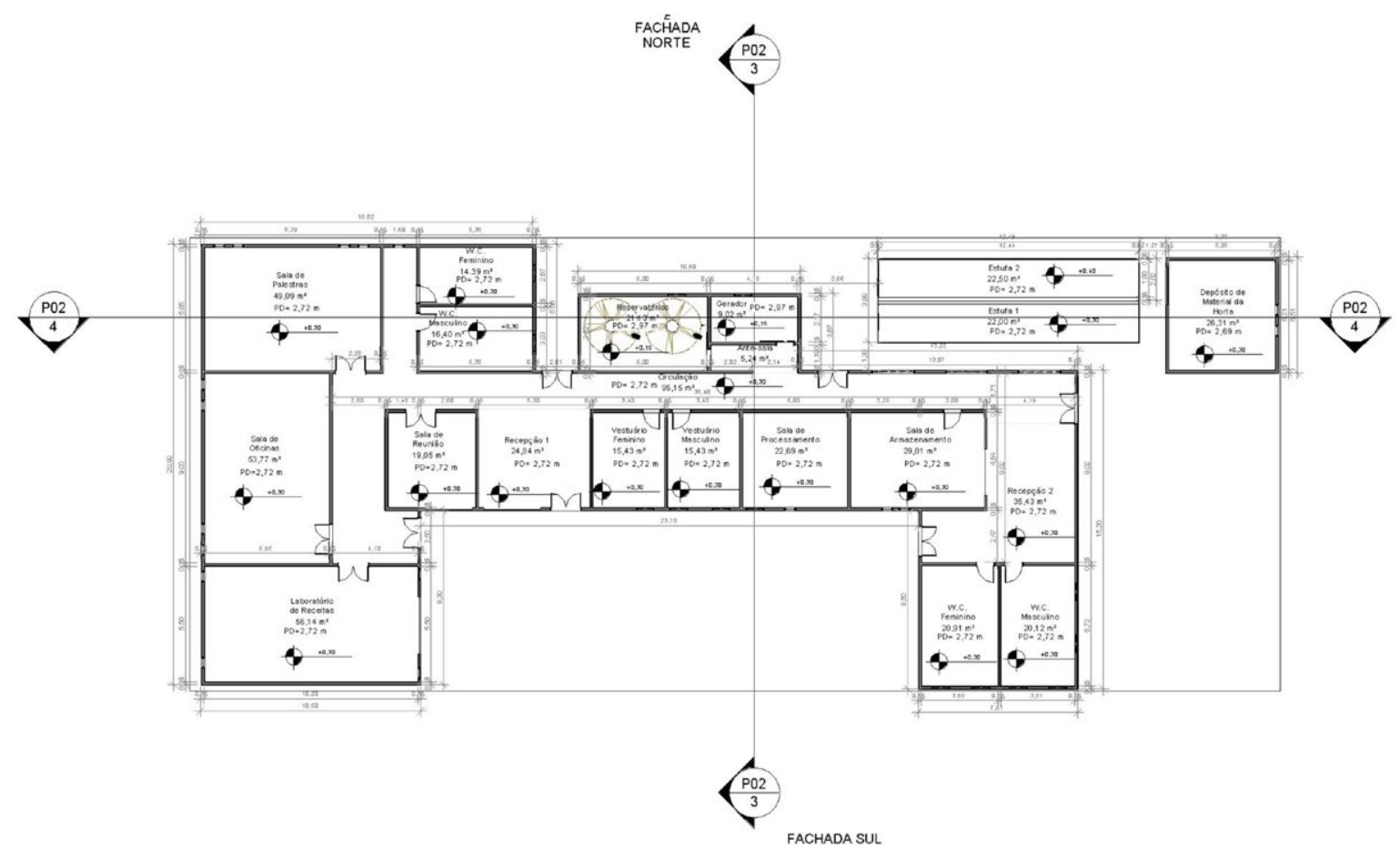

Figura 2. Layout de Centro administrativo e comunitário, estufas e depósito de material de horta Fonte: Elaborado pela autora (2015).

A horta possui uma área de $1.573,24 \mathrm{~m}^{2}$ onde estão as seguintes produções com as respectivas áreas de produção e quantidade de mudas listadas a seguir: 


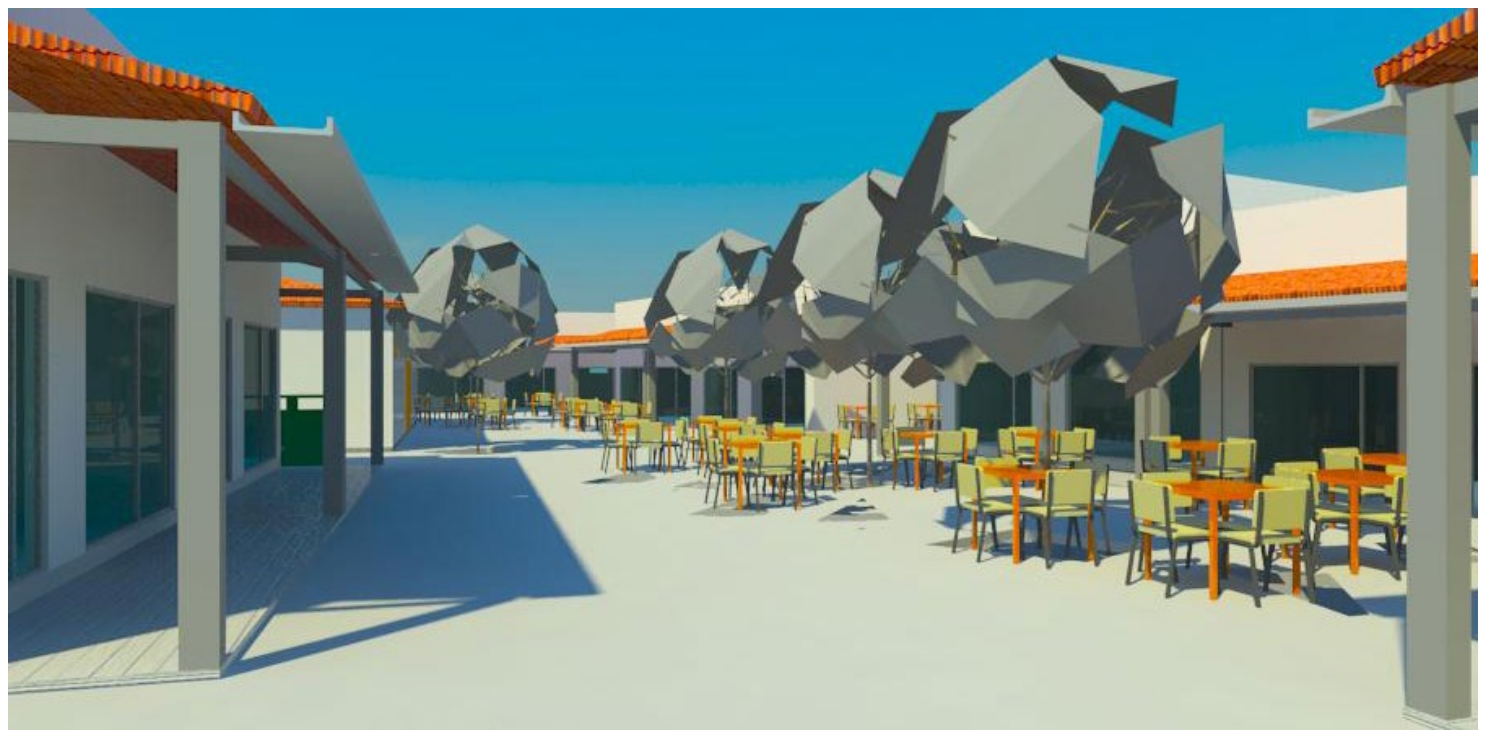

Figura 3. Perspectiva 1 - Mercado

Fonte: Elaborado pela Autora (2015)

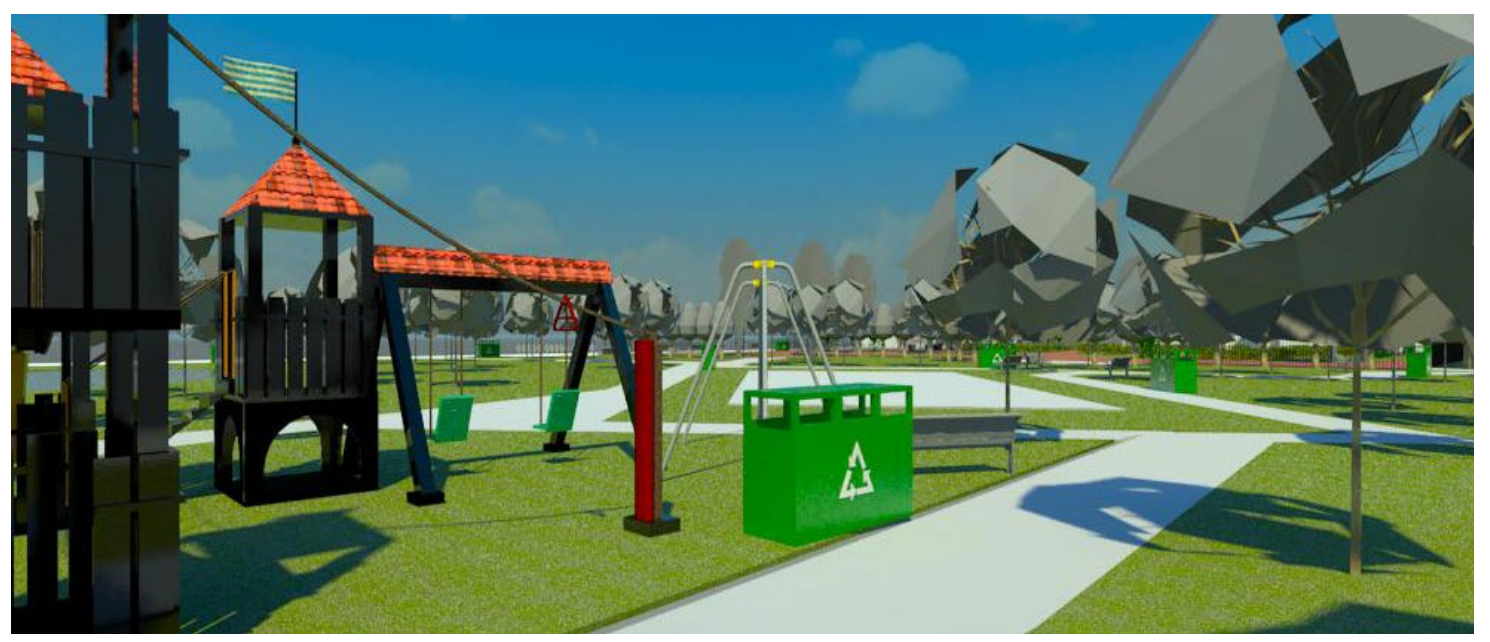

Figura 4. Perspectiva 2 - Playground

Fonte: elaborado pela Autora $(2015$ 


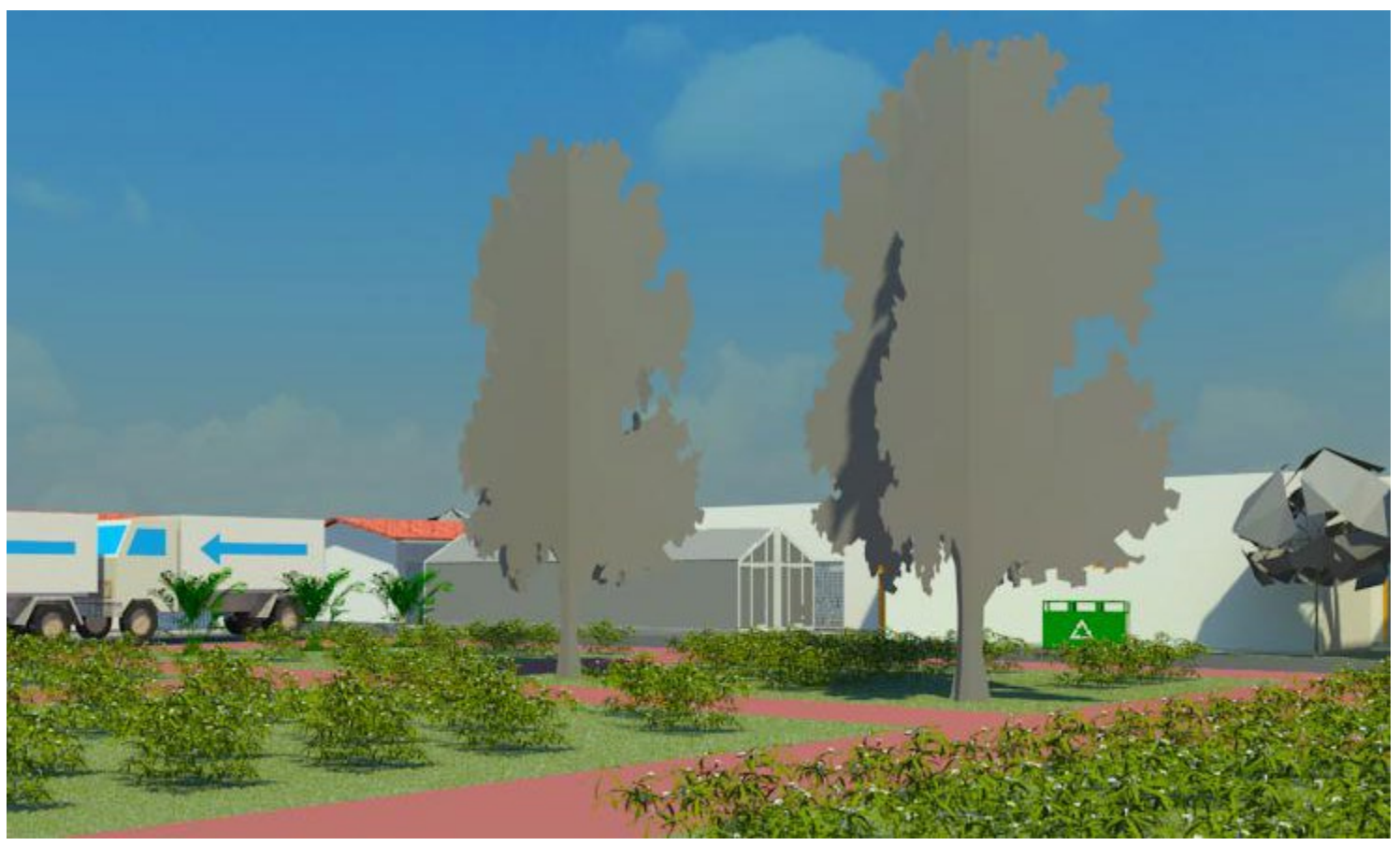

Figura 5. Perspectiva 3- Horta

Fonte: Elaborado pela Autora (2015)

\section{CONCLUSÃO}

A agricultura urbana é considerada uma alternativa importante na aquisição de alimentos saudáveis, pois com a evolução do agronegócio, sementes transgênicas em consonância com a produção em larga escala de alimentos há, concomitantemente, a necessidade de uso cada vez maior de agrotóxicos acarretando alergias, intolerâncias alimentares e intoxicações. A agricultura fundada nos ditames da agroecologia por meio de projetos de implantação de hortas urbanas nos espaços ociosos das cidades apresenta-se como alternativa fácil, econômica e viável juntamente a outros sistemas de produção de alimentos orgânicos para melhoramento dos efeitos que 0 crescimento urbano acarreta à saúde e bem-estar dos indivíduos que compõem as comunidades urbanas.

A apropriação do espaço urbano, em especial o espaço sem perspectiva de uso, é um potencial que necessita ser explorado por uma " teia" de ações conjuntas em diversos níveis, a começar pelo nível local.

0 comprometimento e a apropriação por residentes próximos a esse terreno devem ser apoiados e incentivados de forma que 0 bairro possa alcançar os mais diversos benefícios com a prática das hortas. Isto, certamente, ajudará a modelar a "autoestima" coletiva a partir da autonomia que o planejamento em comunidade poderá ensejar por meio dos objetivos almejados ao alcance de metas em que uma comunidade possa se sentir orgulhosa, e isto somente será alcançável de uma maneira onde cada um como interessado tenha plena consciência do poder transformador que tem e pelo que é responsável.

Infelizmente, no contexto presente, ainda é possível observar o mau uso dessa prática que pode criar severas consequências que vão desde a disseminação de agentes patológicos nas áreas urbanas até mesmo a destruição de ecossistemas frágeis.

Nesse caso, faz-se importante o mapeamento dos riscos e potencialidades desses terrenos. Também por meio da elaboração do estudo preliminar de uma fazenda urbana, na avenida Presidente Médici, foi possível o reconhecimento da importância de especialização e treinamentos em forma de técnicas de cultivo, tecnologias, para que a prática de tal atividade possa ser melhor compreendida e implementada por uma sociedade contemporânea, que ainda aprende com dificuldades a lidar com o meio ambiente. 


\section{REFERÊNCIAS}

BRASIL. Constituição da República Federativa do

Brasil. 16. ed. São Paulo: Atlas, 2015.

BRASIL. Lei $\mathbf{n}^{\circ} \mathbf{1 0 . 2 5 7}$, de 10 de julho 2001. Regulamenta os arts. 182 e 183 da Constituição Federal, estabelece diretrizes gerais da política urbana e dá outras providências. Palácio do Planalto, Brasília, DF,10 jul. 2001.

BRASIL. Lei $\mathbf{n}^{\mathbf{0}} \mathbf{4 . 5 9 0}$, de 11 de janeiro de 2006. Dispõe sobre a construção, reconstrução e conservação de muros e calçadas e dá outras providências. Disponível em: http://www2.saoluis.ma.gov.br/custom_files/ File/Lei\%20n_4590.2006.pdf. Acesso em: 12 jul. 2015.

BURNETT, F. L. Uso do solo e ocupação territorial na região metropolitana de São Luís: dinâmica econômica e realidade sócio-ambiental dos Municípios de São Luís e São José de Ribamar. São Luís: Setagraf, 2012. $84 \mathrm{p}$.

CARNEIRO, F. F.; AUGUSTO, L. G. S.; RIGOTTO, R. M.; Friedrich, K.; BÚRIGO, A. C. (Org.). Dossiê ABRASCO: um alerta sobre os impactos dos agrotóxicos na saúde. Rio de Janeiro: EPSJV; São Paulo: Expressão Popular, 2015.

SALVADOR, C. A. Agricultura orgânica. Secretaria da Agricultura e do Abastecimento. Paraná, 2011. Disponível em: <http://www.agricultura.pr.gov.br/arquivos/ File/deral/agricultura_organica_2011_12.pdf>. Acesso em: 15 nov. 2015.

SÃO LUÍS. Lei 3.253, de 29 de dezembro de 1992. Dispõe Sobre o zoneamento, parcelamento, uso e ocupação do solo urbano e dá outras providências. Disponível em: http://www.gepfs.ufma.br/legurb/LEl\%20 3253.pdf. Acesso em: 12 jul. 2015.

SILVA, G.; ROMER0, M. Sustentabilidade urbana aplicada: análise dos processos de dispersão, densidade e uso e ocupação do solo para a cidade de Cuiabá, Estado de Mato Grosso, Brasil. EURE
(Santiago), v. 41, n.122, p. 209-237, 2015. Disponível em: <http://www.scielo.cl/scielo.php?pi$\mathrm{d}=$ S0250-71612015000100010\&script=sci_arttext > . Acesso em: 12 jul. 2015.

SILVA, J. A. Curso de direito constitucional positivo. 17. ed. rev e atualizada. São Paulo: Basso, 2015.

SOUZA, E. Como fazer cidades: "guerrilheiros urbanos" e os jardins urbanos em Berlim. 2012. Disponível em: <http://www.archdaily.com.br/br/01-62376/ como-fazer-cidades-guerrilheiros-urbanos-e-0sjardins-urbanos-em-berlim>. Acesso em: 4 dez. 2015.

Recebido em:31 de março de 2017 Aceito em: 11de maio de 2017 